Rafi'atun Najah Qomariah: 'Ilm al Șarf Bain al Nazriyyah wa al Tatbīq 'Ind al Qudamā' wa al Muhdisin

\title{
علم الصرف بين النظرية والتطبيق عند القدماء والمُحُدْثين
}

\section{Rafi'atun Najah Qomariah}

Pascasarjana UIN Maulana Malik Ibrahim Malang

Email: rafiatunnajah93@gmail.com

\section{مستخلص البحث}

أهداف البحث لمعرفة نظريات علم الصرف عند القدماء والمحادين وكيف

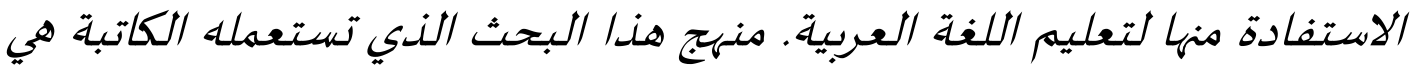

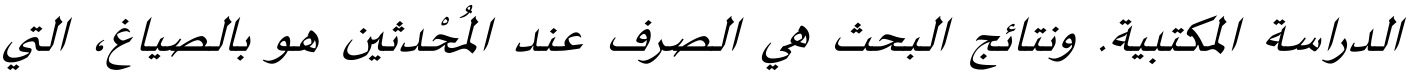

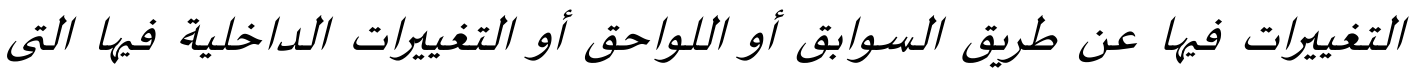

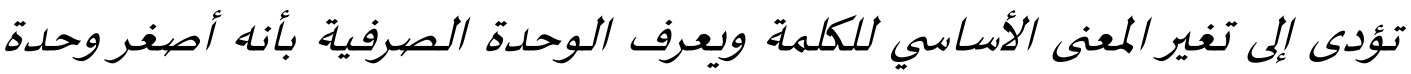

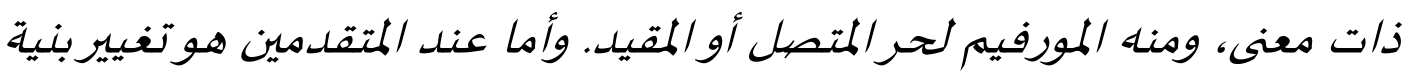
الكلمة بحسب ما يعرض لها. ولا يتعلق التصريف إلا بالأسماء المتمكنة والأفعال

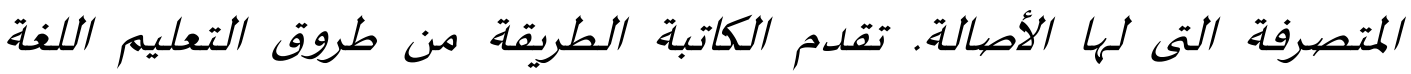
العبية الحلديثة المناسبة بتعليم علم الصرف ليس بحفظ فقط. هي الطريقة

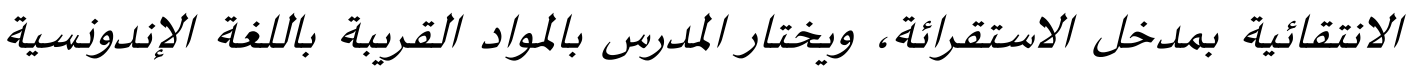
حتى البعيدة.

\section{الكلمة المقيدة: علم الصرف، تعليم اللغة العربية، التربية.}

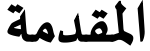

قال عبد الرزاق السعدي أحد إعلام اللغة والأدب: هالعربية لغة كاملة معجبة تكاد تصور ألفاظها مشاهد الطبيعة، وتمثل كلماتها خطوات النفوس،

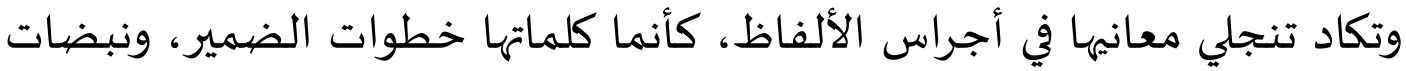


Rafi'atun Najah Qomariah: 'Ilm al Șarf Bain al Naẓriyyah wa al Tạtbì 'Ind al Qudamā' wa al Muhdisin

القلوب، و نبرات الحياةه.'وكما عرف أن هذه اللغة تكوين كلماتها تؤخذ من ثلاثة الأحرف الأصلي (triliteralitas) التي تكون بعملية التصريف. وهذه الظواهر دفعت العلماء قديما وحديثا إلى القيام بالبحث للكشف عن أسرار اللغة. والكلام عن اللغة العربية يقتصر عند اللغويين من ناحية ظواهر الصرفية ونظرياتها. وطروق التعليم القديما في المعاهد أو المدارس في تعليم علم الصرف بالحفظ وتفريق بعلم النحو، حتي لو الطلبة يحفظون لكنهم لم يستطيعوا أن يسخدموا و يطبقوا في الجملة أو في الكلام. فلذالك يدفع إلى تأثير السلبيات لأن الحفظ هو شيئ ثقيل فالطلبة يخفون تعليماه وسيقولون بأن علم الصرف صعبة جدا. والصعوبات الأخرى عند الطلبة ليعرفون الكلماة الأسـاسية في اللغة العربية، مثلا إذا تريدون أن يعرفوا كلمة فتبحثون في القموس ولكنهم لم يعرفو عن الكمة أساسيتها فهم لم يجدوها.

إن البحث عن النظرية اللغوية الصرفية تعالج التركيب الصرفي في المقام الأول وتختلف عن اللظرية النحوية يرجع إلى تسليمنا بضرورة أن تكون للصرف نظريته الخاصة باه التي يلزم أن تختلف عن نظرية النحو العامة، لأن موضوع الدراسـة أو الظاهرة التي يتناولها العلمان جِدُّ مختلفة، إذ يقوم النحو على دراسـة التركيب النحوي المتمثل في الجمل فضلا عن النص الذي فصل عن دراسة تركيب الجملة، وجعل فرعا مستقلا على حين يقوم الصرف على دراسـة تركيب

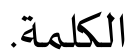
إن نظرة فاحصة لموضوعات الدرس الصرفيّ توقع في قنوات متشـابكة من الهِيّيخ تدخل كل منها على الأخرى تارة وتختلف عنها معنى أو مبنى تارة أخرى. 'عبد الرزاق السعدي، مقومات العالمية في اللغنة العببية وتحدياتها في عصر العولمة، بحث منشورفي

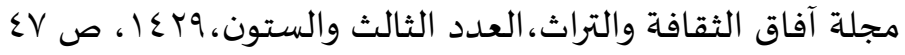

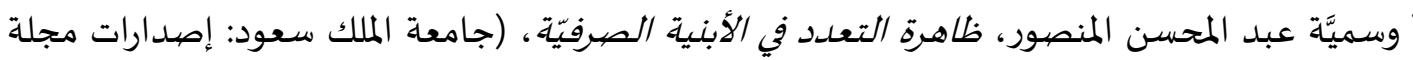

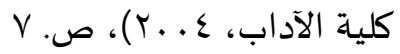


Rafi'atun Najah Qomariah: 'Ilm al Șarf Bain al Nazriyyah wa al Tạtbī 'Ind al Qudamā' wa al Muḥdisin

والحقيقة أن المقارنة بين العلماء اللغويين القدماء والمحدثين تمثل نقطة جدل شـيد بين اللغويين الذين يأخذون موقفين متقابلين. يقرر بعض اللغويين التشاباه بين هذين الدرسين اللغويين من خلال بعض المفاهم التي تتصل بالدرس الصرفي، وتعالج ظاهرة التعدد كمفهوم الأصل والفرع ونظرية العلامة. علم الصرف عند القدماء هو ما نشأة الصرف و تطوره في كل المراحل قبل قرن الرابع عشر من الهجري. وأما بعد قرن الرابع عشر من الهجري مع إتصاله مع علم اللغة الحديث من الغربيون و تداخلهم في علم اللغة العربية فقد يؤثرعلم اللغة العجم على علم الصرف، فيسمون علماء اللغة العربية هذا الواقع بعلم الصرف عند المحدَثين. وعلم الصرف المحدَثين في علم اللغة الحديث يبحث فى الوحدات الصرفية (المورفيمات) التى تؤدي وظائف محددة في الصيخ، فهو يختلف عن علم الصرف عند القدماء من الصرفين العرب الذين كانوا يرون أن التصريف يختص بالبحث فى تغيير اللفظي الذي لا يؤدى إلى تغيير فى المعنى، وتغيير الذي يحدث فى الأبنية و يترتب علياه تغيير فى المعنى. تعد على أية حال، ظاهرة تعدد الوحدات اللغوية من أبرز ما عني باه الدرس اللغوي التقدماء مثلما يعنى بها الدرس اللغوي المحدَثين اليوم. إن هذا يعرض المفاهيم اللغوية العربية والغربية التي تعالج مشكلة واحدة معا للوصول إلى مدى التشاباه والتخالف بين الممفاهيم المتقابل أو المتشابهة. ستقوم هذه المجلة تحت الموضيوع: "علم الصرف بين النظرية والتطبيق عند القدماء والمُحْدَثْين". وأهداف البحث لمعرفة نظريات علم الصرف عند القدماء والمحدثين وكيف الاستفادة منها لتعليم اللغة العربية.

, El-Wasathiya: Jurnal Studi Agama, 2016, h 50-51 علم الصرف: نشأته وتطوره Widan Nafi', 
Rafi'atun Najah Qomariah: 'Ilm al Șarf Bain al Nazriyyah wa al Tạtbìq 'Ind al Qudamā' wa al Muhdisin

\section{منهجية البحث}

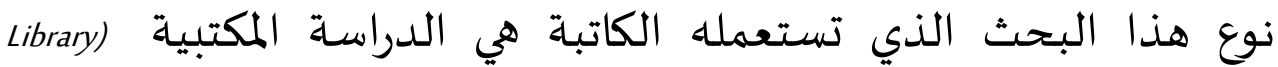
(Research نظريات علم الصرف.

والأساليب التي تسلكها الكاتبة لجمع هذه البيانات، هي بتحديد المواد عن

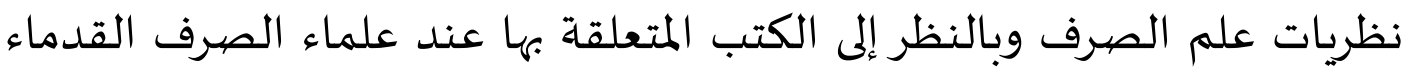

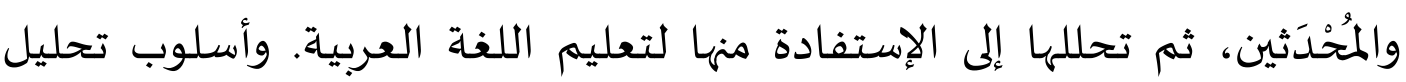

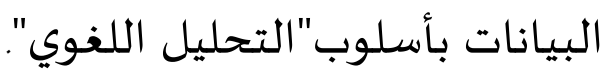

\section{نتائج البحث ومناقشتها}

تلاحظ الكاتبة أن الصرف لغة مأخوذ من مصددر المجرد الثلاثى "صَرَفَ "

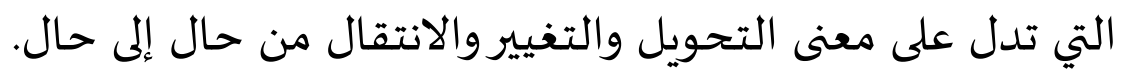

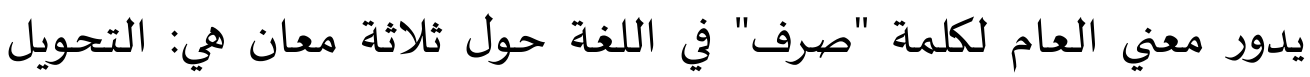
والتغيير، اي تغيرها من جهة الي جهة أخرى، والإنتقال، ومنه صرف الدراهم، أي: نقلها من مللك شخص ال شخص آ آخر. أما في الاصطلاح: الصرف هو تحويل الأصل الواحد إخدر إلى أمثلة مختلفة لمعان مقصودة، لاتحصل تلك المعاني إلا بهذا التغيير. وذلك كتحويل المصديدر

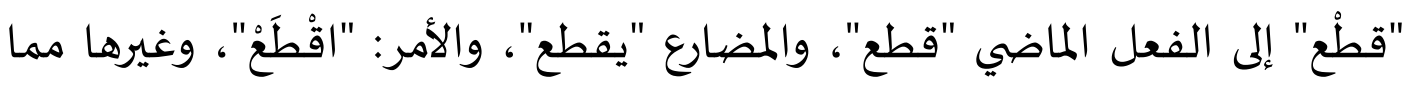
يمكن أن نتوصل إليه من مشتقات تتصرف عن الكلمة الأصل كاسم الفاعل،

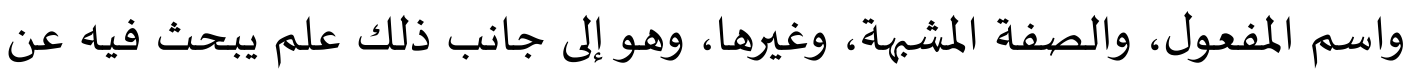

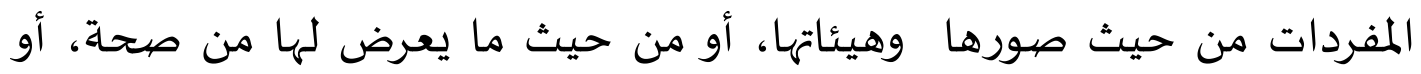

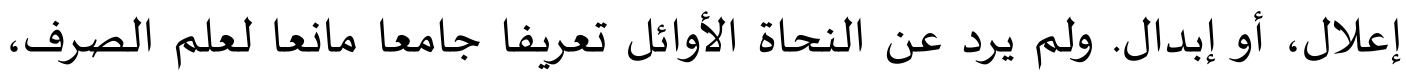

"حسان بن عبد الله الغيمان , الواضح في الصرف,(سعودية : جامعة الملك الصعود,11 .r), ص. 10 
Rafi'atun Najah Qomariah: 'Ilm al Șarf Bain al Nazriyyah wa al Tatbīq 'Ind al Qudamā' wa al Muhdisīn

وغاية ما عرف باه هذا العلم ما ورد عن ابن الحاجب في حاشيتاه حيث قال: "التصريف علم بأصيول تعرف بها أحوال أبنية الكلم التي ليست بإعراب". وأما علم الصرف هو أصول وقواعد، تعرف بها بأبنية الكلمة، صيغها الأصلية والعارضية،، وما يلابسها من تغير معنوي في مدلولها، مصبدره البناء المحدث، بالتصغير أو النسبة أو التثنية أو الجمع أو التعنيث في الأسماء،

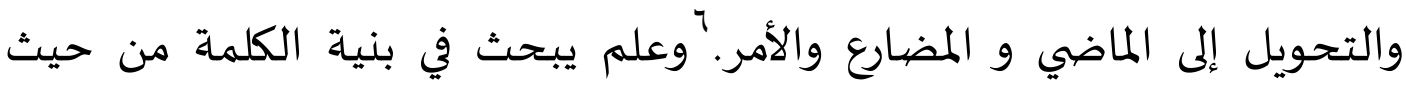
بناؤها ووزها وما يطرأ على تركيبها من تغيير. وموضعاء: الاسم غير المبني، والفعل

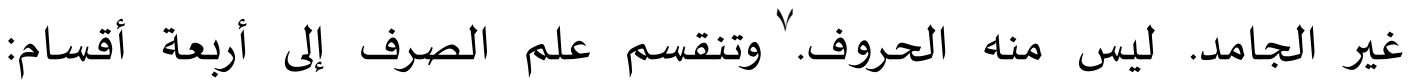
الوصفية،، والتارخية،، والمقارنة، والعامة بحسب اعتبارات التقسيم السـابقة في الفوناتك. وقيل أن علم الصرف هو العلم بأحكام بنية الكلمة، وبما لأحرفها من أصالة وزيادة وصحة وإعلال وإبدال وشبـه ذلك. فَهـذا العلم نعرف ما يمبغي أن أن يوجد في كلمة قبل ترتبها لإي الجملة. تعرف الأوربية الحديثة علم الصرف بأنه: "البحث في نشأة الكلمات والتغيرات التى تطرأ على القواميس مطهرها الخرجي فى الجملة". وتدل مادة "صرف" في العربية على معنى التغيير. ويشمل الصرف أو تصر يف كل ما يندرج

رضي الدين محمد بن الحسن الاستراباذي، شرح شافية /بن الحاجب، ج ا (بيروت: دار الكتب العلمية، ا " فخرالدين قباوة، تصريف الأسماء والأفعال، (بيروت: مكتبة المعارف، دون السنة) ص سا

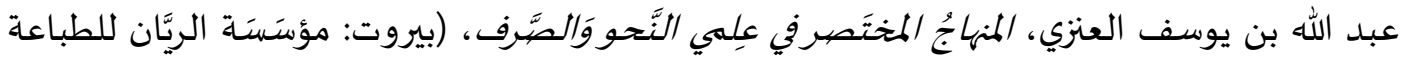

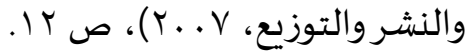

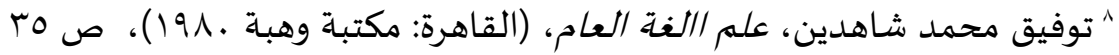

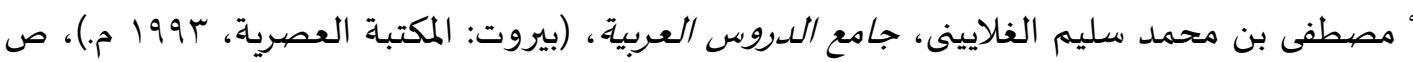


Rafi'atun Najah Qomariah: 'Ilm al Șarf Bain al Nazriyyah wa al Tatbīq 'Ind al Qudamā' wa al Muhdisīn

فى نطاق الإشتقاق (أى التغيير المرتبط بالمعنى) وكذلك ما يندرج فى نطاق الإعلال وما إليه (أي التغيير الصوتى). '. واستنتجت الكاتبة من جميع التعريفات المذكورة، فعلم الصرف هو علم من علوم اللغة العربية الذي يبحث عن احوال بنية الكلمة من تحويل الأصل الواحد إلى أمثلة مختلفة، تحويل من أصل الكلمة إلى المجرد والمزيد وحروف

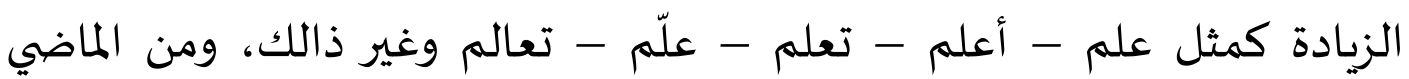
والمضيارع والأمر كعلم - يعلم - اعلم، ومن الأفعال إلى الأسماء كعلّم - معلّم -

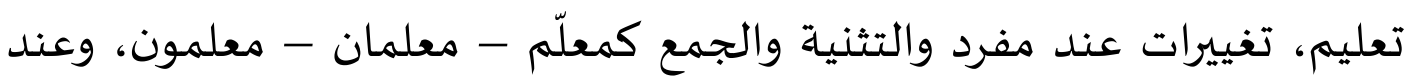
الذكير والتأنيث كمعلّم - معلّمة، وللفعل عند اتصاله بالضمائر كعلّم - علّما علّموا وغير ذالك. نشأ علم الصرف مع علم النحو كالعلم الواحد فقد تطور الصرف وحده منفصلا لا يخلط علم النحو. لأن الصرف أحد علوم الأدب الأثنى عشر التي يحترز بها عن الخلل في كلام العرب وبعده لفظا أو كتابتاه، وكان علماء النحو قديما هم علماء اللغة والأدب لأن التمايز بين هذه العلوم ل يتم إلا بعد حين، وقد نشأ علماء النحو والصرف معا بعد ما أحس العرب بحجاتهم إليها، وذالك لحفظ القرآن الكريم من اللحن الذي انتشر بدخول شعوب غير عربية في الإسلام، ولفهم النص القرآنى باعتباره مناط الأحكام التى تنتظم الحياة. وتطور علم الصرف في مرحلة أولى كان ينسرب بين مباحث النحو تأليفا كما نرى كتاب سبوياه، وتناظرا كما تحدثنا مناظرات نحوي هذه الفترة، و من

"' الطيب البكوش، التصريف العربي من خلال علم الأصهوات الححيث، (بدون المدينة: المكتبة الإسكندر

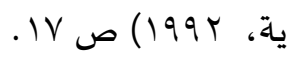

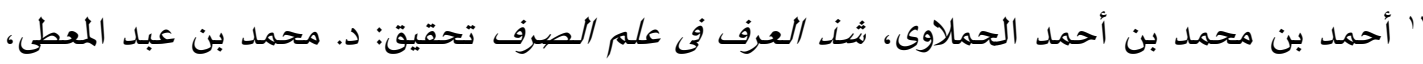

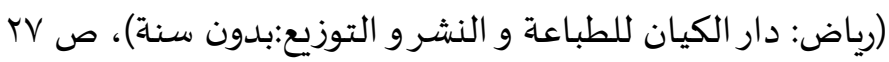


Rafi'atun Najah Qomariah: 'Ilm al Șarf Bain al Nazriyyah wa al Tatbīq 'Ind al Qudamā' wa al Muhdisin

ذلك ما بدأ باه مجلس سبويه مع الكسائى و أصحبه بحضرة الرشيد.ب' ثم يستمر بالمرحلة التي تألف كتب بعدد كبير خاصة لعلم الصرف، إما تحمل اسم التصريف، و إما تحمل أحد مباحثه أو إحدى مسائله. وتبدأ بعلى بن حمزة الكسائى ت 1119 هـ الذي ألف كتاب فى المصادر، وبأبى جعفر الروسي المتوفى زمن

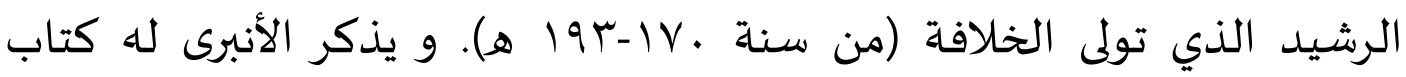
"التصغير". "فّعلم الصرف في هذه المرحلة يبحث منفصلا لعلم النحو. ثم المرحلة التي بلغت الدراسات الصرفية أوجها، وهي التى نحددها بالقرنين السادس والسابع الهجريين، وفيها اكتمل صرح التصريف، وبلغ التأليف ذروته على يد علمائها الذين جاءت مؤلفاتهم غاية في الإستيعاب لجميع أبواب التصريف، فوضعوا أهم مصنفاته وأدقها وأكملها وأجودها تهذيبا وتوضيحا ومنهجة. وكان إمام هذه الفترة ونجمها اللامع وأستاذها ابن القطاع الصقلى، الذي أدخل الصرف بتأليفه في الأبنية مجالا جديدا، والذي ظهر تأثيره واضحا في مؤلفات من جاء بعده كابن عصفور وأبى حيان، وكتب اللغة كالقاموس وشرح

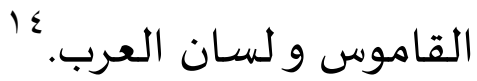

ويستمر ذلك التطور حتى وصل هذا العلم إلى القرن الرابع العشر ويتصل بعلوم اللغة الحديث من الغربيين. علم الصرف بين المتقدمين والمحدثين كان المتقدمون يرون أنّ التصريف قسم من النحو وأنّ مدلول النحو عام يشمل جميع القواعد والمسـائل التى تتعلق

r' الزجاجى، مجالس العلماء تحقيق الأستاذ عبد السلام هارون، (القاهرة: مكتبة الخانجى، 1999)، ص 9. ז' أبى البركات الأنبارى، نزهة الألباء فى الطبقات الأدباء تحقيق د. إبراهيم السامراء، (الأردون: المنار، 71 (1910)، (1910 ؛' أحمد محمد عبد الدائم عبد الله، ابن القطاع و أثثه في الدراسات الصرفية مع تحقيق كتابه "أبنية

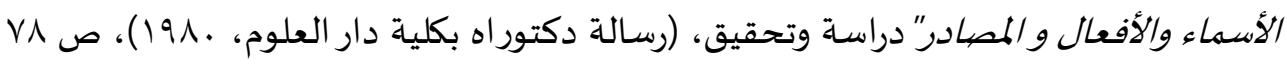


Rafi'atun Najah Qomariah: 'Ilm al Șarf Bain al Naẓriyyah wa al Tạtbì 'Ind al Qudamā' wa al Muhdisin

بآخر الكلم العربية وغير الآخر، ولهذا عرفوا النحو بما يشمل التصريف فقالوا: علم يبحث عن أحوال الكلم العربية إفرادا وتركيبا، وكان الصرف أو تصريف يطلق على مبحث خاص من مباحث النحو يقال له الإشتقاق، أو اختراع الصيغ العرب على وزن ما استعملتا، ثم تعمل فى هذا اللفظ ما يقتضياء قياس كلاههم من إعلال وإبدال وإدغام وغير ذلك كأن تبنى من خرج عللى مثال دحرج، و من وأى بمعنى وعد على مثال كوكب. هذا هو معنى التصريف عند المتقدمين من هن النحاة، ولعل السر في هذه التسمية كثرة ما يعترى هذه الصيغ المخترعة من التغيير و التحويل.

والقدماء يرونه في الكلمة المتصرفة سواء أكانت اسما متمكنا أو فعلا متصرفا فقط. أما المحدثون فيرون ان كل دراسة تتصل بالكلمة أو أحد أجزائها وتؤدى إلى خدمة العبارة أو الجملة أو بعبارة بعضههم فؤدى إلى اختلاف المعانى النحوية كل دراسـة من القبيل هي صرف. وعلى ذلك فلا يمكن استبعاد أي صيغة لغوية، فالأسماء غير المتمكنة بل إن بعض حروف الجر مثل (على و إلى) يتغير ألفة إلى ياء عندما يلحق ضمير وصل فى نحو (عليك و إليك) بل تتغير وظيفتها إلى معنى اسم الفعل. وأما عند العلماء اللغوي الحديث، هم لا يبحثون عن "الكلمة" ولكن مرفيم هو أصغر صيخ للغة التي لا يمكن تقسيمها إلى أقسام أصغر منها، المثال في اللغة الإندونسية، الكلمة "putus" إذا كانت مقسمة إلى pu و وtus، فلا يعرف بمورفيم لأنه ليس فيه المعنى، إما معنى معجمي أو معنى نحوي. وُلذّالك، مرفيم هو أصغر صيغة اللغة التي لا يمكن تقسيمها، ولها المعنى النحوي والمعجمي. فالصرف عند المحدثين يبحث في الوحدة الصرفية morphemes وأهم أمثلتها الكلمات و أجزاءها ذات المعانى الصرفية كالسوابق واللواحق. لا يعرض

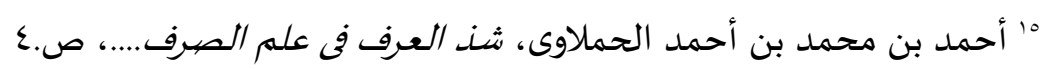


Rafi'atun Najah Qomariah: 'Ilm al Șarf Bain al Nazriyyah wa al Tạtbīq 'Ind al Qudamā' wa al Muhdisin

الصرف كذلك للصياغ اللغوى فياه ويصنعها إلى أجناس وأنواع بحسب وظائفها كأن يقسمها إلى أجناس الفعل، والإسم، والإدارة، أو ينظر إليها من حيث التذكير والتأنيث، ومن حيث الإفراد ولتثنية و الجمع إلى غير ذلك من كل ما يتصل باصيغ المفرد. والمحدثون من علماء اللغة العرب يقسمون الكلام سبعة أقسام، هي: الإسم، الصفة، الفعل، الضمير، الخالفة، الظرف، الأداة. و إذا كان التصريف عند الصرفيين العرب يبحث فى التغيير المختص بالكلم المفردة، فيتناول الإعلال والإبدال، والحذف، والزيادة، والإدغام؛ فإن التغيير عند علماء اللغة الغربيين المحدثين على ضربين: ا. تغيير صرفى محض،ب. تغيير شامل. والتصريف في علم اللغة الحديث هو ثانى أربعة مستويات تتدرج تحت مصطلح (علم اللغة) الذي يعنى بدراسة المستويات الأربعة، وهذه المستويات هي:ا. مستوى الأصيوات، r. مستوى الصرف، ب. مستوى النحو، ع. مستوى المفرداتل. ويوجد في منهج الصرف الحديث ما يسمى بالسوابق واللواحق. والوحدة الصرفية هي ما يطلق عليه الغربيون مصطلح مورفيم وقد قال "ماريوباي" فى تعريفه وأقسامه: ويعرف المورفيم على أن (morphem) أصغر وحدة ذات معنى. فبينما يصف النحو كلمة "مؤمنون" أنها تشتمل على أصل هو "مؤمن" ونهاية تصريفية تفيد الجميع هي "ون" يصف علم اللغة التركيبى الحديث "مؤمن" و"ون" على أنهما مورفيمان، أو حدتان ذواتا معنى، تحمل إحداهما المعنى الأساسي للكلمة، وتحمل الثانية فكرة الجمع الإصافية. 19 فالوحدة الصرفية قد تكون كلمة أو جزءا من كلمة، وهي المصطلح الأسـاسي في "محمد على النجار، التبيان فى تصريف الأسماء، (القاهرة: الهيئة المصرية العامة للكتاب، 1991)، ص $10-17$

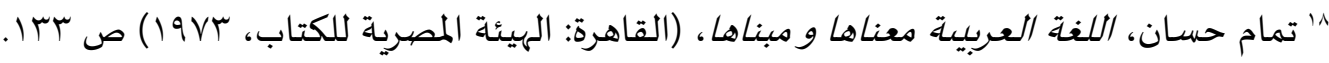

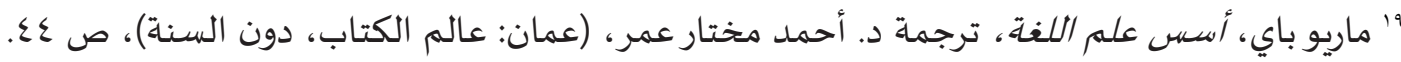


Rafi'atun Najah Qomariah: 'Ilm al Șarf Bain al Naẓriyyah wa al Tạtbì 'Ind al Qudamā' wa al Muḥdisin

التحليل الصرفي الحديث. وفى الصرف مورفيمات لها أسماء خاصية، كالطلب

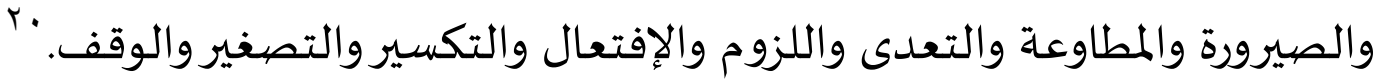
وعلم الصرف عند "ماريو باي" وللكلمات يمكن أن تمثل سلاسل من مورفيم واحد أو أكثر أي: إن المورفيمات أصغر الصيخ، والكلمة في التعريف الكلاسيكي البلومفيلدي "على الرغم من أنه ليس مرضيا إلا بشكل جزئي" أصغر الصيغ الحرة "أي: الصيغ التي لا تتكون كلية من صيغ حرة أصغر"، والصيغة الحرة في مقابل الصيغة المقيدة هي تلك الصيغة التي يمكن أن تكون مع منحنى تطريزي مناسب قولا "وليس بالضرورة جملة تامة" في بعض السياقات المعتادة

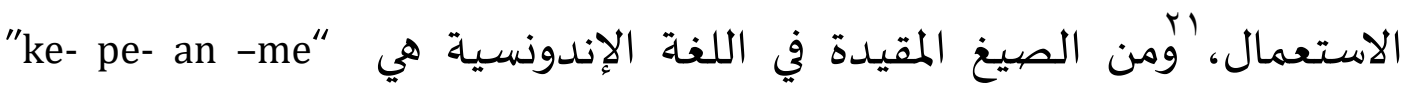
وغير ذالك، كمثل في كلمة "penulis"، من الصيغة المقيدة وأما tulis الصيغة الحرة. وأما في اللغة العربية من الأمثلة الصيغ المقيدة "وا" (واو الجماعـة) في الكلمة "كتبوا"، و"ال" (علمة التعريف) في الكلمة "الطالب"، فكلمة "طالب" re-, -ist, -ed, - "كتب" الصيغة الحرة. وأما الصيغ المقيدة في اللغة الإنجلزية منها

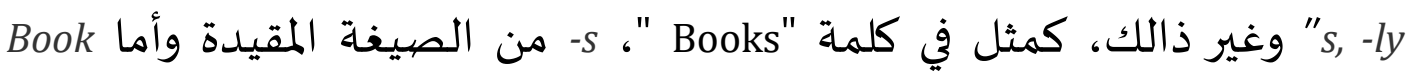
الصيغة الحرة.

بناء على ذالك، فالصرف عند الحدثين هو بالصياغ، التي التغييرات فيها عن طريق السوابق أو اللواحق أو التغييرات الداخلية فيها التى تؤدى إلى تغير المعنى الأساسي للكلمة ويعرف الوحدة الصرفية بأنه أصغر وحدة ذات معنى، ومنه المورفيم لحر المتصل أو المقيد. وأما عند المتقدمين هو تغيير بنية الكلمة بحسب ما يعرض لها. ولا يتعلق التصريف إلا بالأسماء المتمكنة والأفعال المتصرفة التى لها الأصالة.

ممدوح عبد الرحمن الرمالى، التحليل الصرفى فى الدرس العبلي التراثى، (إلماني: مكتبة دار العلوم

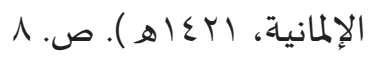

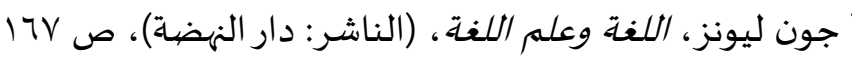


Rafi'atun Najah Qomariah: 'Ilm al Șarf Bain al Nazriyyah wa al Tạtbīq 'Ind al Qudamā' wa al Muhdisin

من الوصف السـابقة يمكن أن يفهم بأن علم الصرف هو من قواعد اللغة العربية التي تحفظ اللسان أو كتابة عن الخطأ في صياغة الكلمات وتعين

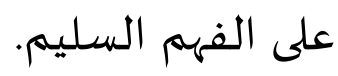
في هذا اليوم تعليم الصرف المنتشر في اندونيسيا، فقد تم التركيز على حفظ القواعد أو المتن باستخدام كتاب أمثلة التصريفية ولفهم المحتوى من قراءة الكتاب. وتقتصر حفظ المتن بالغناء. ولكن الآن بهذه الطريقة التقليدية تؤثر صعوبات للطلبة في المعاهد أو المدارس في تعليم علم الصرف بالحفظ وتفريق بعلم النحو، حتي لو الطلبة يحفظون لكنهم لم يستطيعوا أن يسخدموا ويطبقوا في الجملة أو في الكلام. فلذالك يدفح إلى تأثير السلبيات لأن الحفظ هو شيئ ثقيل فالطلبة يخفون تعليمه وسيقولون بأن علم الصرف صعبـة جدا. وهم مملون والصعوبات الأخرى عند الطلبة ليعرفون الكلمة الأساسية في اللغة العربية، مثلا إذا تريدون أن يعرفوا كلمة فتبحثون في القموس ولكنهم لم يعرفو عن الكمة أساسيتها فهم لهم يجدوها. كما التطورات العصرية والتعليمية فتعليم علم الصرف يلازم أن يطور أيضا، بلا استخدام نظريات عند القدماء فقط بل عند المحدثين أيضا. لكي علم لماه الصرف لايعتبر بالعلم القديم والممل والصعبة. فالكاتبة تقدم طريقة من طروق التعليم اللغة العربية المناسبة بتعليم علم الصرف. يعني الطريقة الانتقائية وهي طريقة تهدف إلى تعليم اللغة العربية

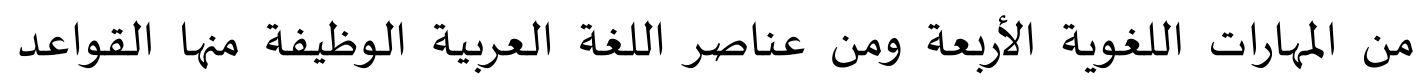
والمفردات وغيرها. لأن تعليم علم الصرف لم تفارق من تعليم اللغة العربية كاملة. وبهذه الطريقه تعليم التصريف الكلمات يمكن أن تتم بمدخل الاستقرائة، يعني ان هذه الطريقة تقوم بتقديم الأمثلة الى الطلبة ومناقشتهم فيها والموازنة بينها واستخلاص القاعدة ثم التدريب عليها، حتى يمكن الطلبة أن يستنتج 
Rafi'atun Najah Qomariah: 'Ilm al Șarf Bain al Nazriyyah wa al Tatbīq 'Ind al Qudamā' wa al Muhdisīn

القواهد الصرفية فيها. وبهذه الطريقة يربي الطلبة يحفظون قواعدها المعطئ سهولة ثم يستخدمونها في تركيب الجملة الصحيحة. لأن علم الصرف هي احدى من القوعد اللغة العربية التي تلازمها بالحفظ. وبالاضافة يقدم الأمثال، المدرس يلازم تقديم أوجه التشابه والاختلافات في اللغة الإندونسية واللغة العربية استناداً إلى نتائج التحليل التقابلي. لأن إذا كان الطلبة يعرفون أن يجد التشاباه باللغة الإندونسية فيسرع إلى فهمهم، ولكن إذا يجد اختلافها فلازم على المدرس يجعل هذه الاختلاف تركز التعليم وتكررها للتدريب، ثم يعطي التمثيل إلى الطلبة ثم يستقلد ويطبّقها إلههم استمرارا. حتى يكون الطلبة لديهم عادات قوية في اللغة العربية فهم يمكنون أن أن يغلبوا على هذه العادة في لغتهم الأم. ووقفا على فهم النظريات تعليم علم النفسي السلوكي تقع الأخطاء اللغوية بسبب النقل السلبي، يعني استخدام (Psychology Behavior) نظام اللغة الأم إلى اللغة المنشودة وأما هذا النظام مختلف في اللغة المنشودة. فالأخطاء الغوية وتأثيرها تنبغي أن تجرد من الطلبة ليكون عملية التعليم اللغة الأجنبية ميسرا. كما قال Robert Lado "أن الظواهر اللغوية متطابقة للغة الأولى سوف تسرع عملية التعلم، ولكن الظواهر الغوية المختلفة ستجعل الحاجز أو المانع" الموبر

كمثل إذا يريد أن يعلّم اسم الفاعل، فالمدرس يشرح عن التشاباه بينهما

أولا يعني اسم الفاعل في اللغة العربية تشاباه بِ nomina بالسـابقة -pe مع أنوعها في الإندونيسية والكلمة بلاحقة r- أو er- في اللغة الإنجلزية، كلها بمعنى من هو يفعل كمثل في اللغة العربية "كاتب" من الكلمة "كتب"، في الإندونيسية " من الكلمة "Tulis"، في اللغة الإنجلزية "writer" من الكلمة "write". ثم يشكلها بزيادة الف بعد أول حرف من حروف الفعل مع كسر الحرف قبل الأخير 
Rafi'atun Najah Qomariah: 'Ilm al Șarf Bain al Nazriyyah wa al Tạtbī 'Ind al Qudamā' wa al Muhdisin

على وزن "فَاعل" .ا... أو من الفعل غير الثلاثي لا تختلف عن صيغة فعل المضيارع إلا في حرف المضيارعة الذي يبدل ميما مضمومة في اسم الفاعل وكسر ما قبل الآخر مـ... وأما في اللغة الاندونسية يكفي بزيادة -pe في أول الكلماة، ولكن في اللغة الإنجيلزية عادة بزيادة r- أو er- في اخر الكلمة.

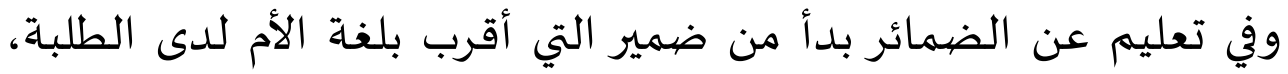

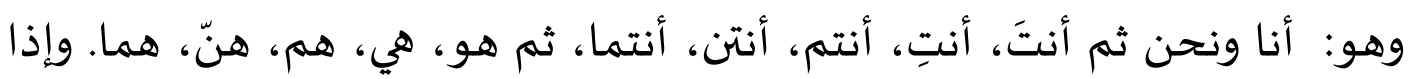
نظرنا إلى مبدأ تعليم اللغة العربية ولا سيما لغير الناطقين بها فقد تم تعليم الضمائر في البداية أو للطلبة المبتدئين من ضمير (أنا، أنت، هو، هي) وهذا يمكن تغييرها.

ويمكن أن طالب تعليم اللغة العربية في الإندونيسية مع خلفية الاجتماعية والثقافية التي أقرب إلى العرب - كمثل الطلبة في المعهد أو الطلبة في المدرسة الإسلامية - فنظام و تركيب اللغة العربية مألوفة معهم. لذالك يمكن أن فنظام و تركيب بين اللغة العربية والإندونيسية يمكن المتحمل. ومن هذه البيانات لا نقل أن ذلك الكتاب غير جيد، ولكن يمكن تيسيرها حتى تيسر الطلبة في التعلم ولإزدياد رغبتهم في تعلم الصرف حتى تناسب المبدأ بهدف من تعليم اللغة العربية هي لغة الاتصال.

ويتضح من الملاحظات السابقة، على المعلمين أن مهتموا بهذا الأمر،

ويغيروا اتجاههم التعليمي، ليكون تعليم الصرف لغير الناطقين بها فعالاً في مساعدتهم لتعلم اللغة العربية واستخدامده على الاتصال.

\section{الخلاصة}

الصرف عند الحدثين هو بالصياغ، التي التغييرات فهها عن طريق السوابق أو اللواحق أو التغييرات الداخلية فيها التى تؤدى إلى تغير المعنى الأسـاسي 
Rafi'atun Najah Qomariah: 'Ilm al Șarf Bain al Nazriyyah wa al Tạtbīq 'Ind al Qudamā' wa al Muhdisin

للكلمة ويعرف الوحدة الصرفية بأنها أصغر وحدة ذات معنى، ومنه المورفيم لحر المتصل أو المقيد. وأما عند المتقدمين هو تغيير بنية الكلمة بحسب ما يعرض لها. ولا يتعلق التصريف إلا بالأسماء المتمكنة والأفعال المتصرفة التى لها الأصالة. الطريقة من طروق التعليم اللغة العربية المناسبة بتعليم علم الصرف. هي الطريقة الانتقائية بمدخل الاستقرائة، وبالاضيافة يقدم الأمثال، المدرس يلازم

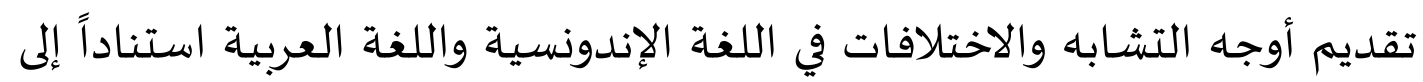
نتائج التحليل التقابلي. لأن إذا كان الطلبة يعرفون أن يجد التشابه التشابه باللغة

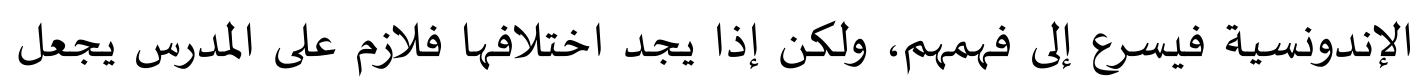
هذه الاختلاف تركز التعليم وتكررها للتدريب، ثم يعطي التمثيل إلى الطلبة ثم يستقلد ويطبّقها إليهم استمرارا.

الاقتراحات

ترجو الكاتبة أن يكون استمرارا أحسن وأكمل من هذه الصحيفة. وتكون هذه الصحيفة أساسا لتخطيط مجهزات تعليم اللغة العربية، إما في تصيميم الكتب الدراسية وإعداد المواد الدراسية واختيار طريقة التعليم والاختبار اللغة العربية. وينبغي على المعلم والمتعلم اللغة العربية الاهتمام بالصعوبات في تعليمها إما في تعليم العناصر اللغوية أم المهارات اللغوياة.

\section{قائمة المراجع}

عبد الرزاق السعدي، مقومات العالمية في اللغة العبربية وتحلدياتها في عصر

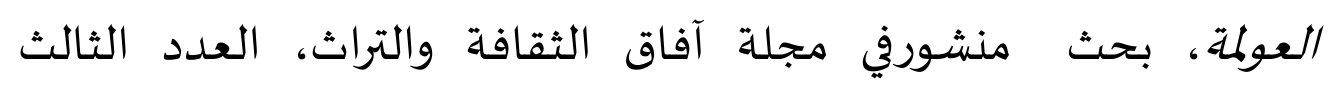

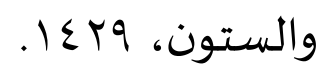


Rafi'atun Najah Qomariah: 'Ilm al Șarf Bain al Nazriyyah wa al Tạtbì 'Ind al Qudamā' wa al Muhdisīin

أبى البركات الأنبارى، نزهة الألباء فى الطبقات الأدباء تحقيق د. إبراهيم

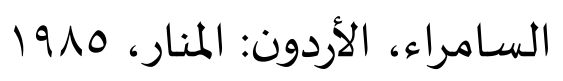

أحمد بن محمد بن أحمد الحملاوى، شن العرف في علم الصرف تحقيق: د. محمد بن عبد المعطى، رياض: دار الكيان للطباعة و النشر و التوزيع:بدون

سنة.

أحمد محمد عبد الدائم عبد الله، /بن القطاع و أثره في الدراسيات الصبرفية مع تحقيق كتابه "أبنية الأسماء والأفعال و المصيادر" دراسة وتحقيق، رسالة

$$
\text { دكتوراه بكلية دار العلوم، . } 191
$$

توفيق محمد شاهدين، علم الغنة العام، القاهرة: مكتبة وهباة . 191. تمام حسان ، اللغة العربية معناها و مبناها، القاهرة: الهيئة المصرية للكتاب، $19 \vee r$

جون ليونز، اللغتة وعلهم اللغتة ، الناشر: دار النهضية. حسان بن عبد الله الغيمان، الواضح في الصرف، سعودية: جامعة الملك

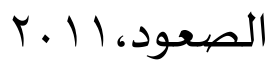

الطيب البكوش، التصر يف العربى من خلال علم الأصيوات الحسليث، بدون المدينة: المكتبة الإسكندرية، بول199.

رضي الدين محمد بن الحسن الاستراباذي، شسح شافية /بن الحاجب، ج ا، 1 ال،

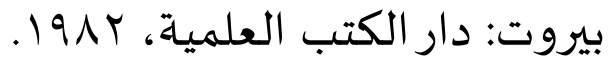

الزجاجى، مجالس العلماء تحقيق الأستاذ عبد السلام هارون، (القاهرة: مكتبة

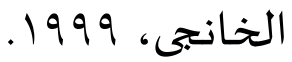

عبد الله بن يوسف العنزي، المنهاجُ المختََصرِفي عِلمي النَّحو وَالصَّرف، بيروت: مؤسَسَسة الريَّان للطباعة والنشر والتوزع، ل . . . . . 
Rafi'atun Najah Qomariah: 'Ilm al Șarf Bain al Nazriyyah wa al Tatbīq 'Ind al Qudamā' wa al Muhdisīn

مصطفى بن محمد سليم الغلايينى، جامع الدروس العربية، بيروت: المكتبة

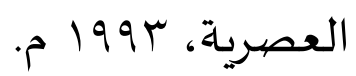

فخرالدين قباوة، تصريف الأسماء والأفعال، بيروت: مكتبة المعارف، دون السنة محمد عبد العزيز عبد الدايم، النظرية اللغوية في التراث العربي، قاهرة: دار

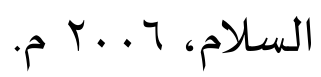

محمد على النجار، التبيان فى تصريف الأسماء، القاهرة: الهيئة المصرية العامة

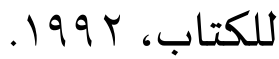

ماريو باي، أسس علم اللغنة، ترجمة د. أحمد مختار عمر، عمان: عالم الكتاب، دون السنة.

ممدوح عبد الرحمن الرمالى، التحليل الصرفى فى الدريس العربي التراثى، إلماني:

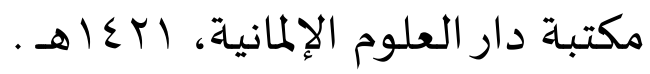

وسميَّة عبد المحسن المنصور، ظاهرة التعدد في الأبنية الصرفيّة، جامعة الملك

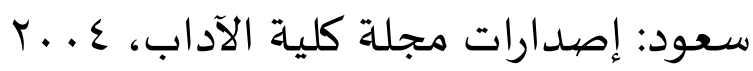

Badudu, J. S, Cakrawala Bahasa Indonesia, Jakarta: Gramedia. 1985

Robert Lado, Linguistik di Berbagai Budaya, terjemahan Soedjono Darjowijoyo, Bandung: Ganec, 1979.

Wildan Nafi'i, علم الصرف: نشأته وتطوره. El-Wasathiya: Jurnal Studi Agama Vol 4, Nomor Desember 2016; P-ISSN 2338-9648, E-ISSN: 2527631X. 